\title{
ERRATUM
}

The Chinese Journal of Mechanics, Vol. 16, No. 2, June 2000, p. 109-124

\section{ON EVALUATION OF LAMB'S INTEGRALS FOR WAVES IN A TWO-DIMENSION ELASTIC HALF-SPACE}

\author{
Chau-Shioung Yeh * \\ Department of Civil Engineering, and Institute of Applied Mechanics \\ National Taiwan University \\ Taipei, Taiwan 10617, R.O.C.
}

Tsung-Jen Teng ${ }^{* *} \quad$ Wen-I Liao ${ }^{* * *}$

National Center for Research on Earthquake Engineering

Taipei, Taiwan 10617, R.O.C.

1. Figures 13 to 18 should be deleted from the paper.

2. The first sentence on page 118, "The corresponding radiation patterns of displacement and traction field at $r=1,10$ and 20 for the case of $m=0$ are depicted in Figs. 12(a) and (b)," should be modified as: "The corresponding radiation patterns of displacement and traction field at $k_{s} r=1,10$ and 20 for the case of $m=0$ are depicted in Figs. 12(a), (b) and (c), respectively."

\footnotetext{
* Professor $\quad * *$ Research Follow $\quad * * *$ Associate Research Fellow
} 